\title{
Radical-induced Oxidation Removal of Mercury by Ozone coupled with Bromine
}

Yaning Sun ${ }^{1}$, Mei Deng ${ }^{2}$, Wenjun Huang ${ }^{1}$, Yongxian Zhou², Yue Zhao ${ }^{1}$, Jisai Chen², Naiqiang $\mathrm{Yan}^{1}, \mathrm{Zan} \mathrm{Qu}^{1, *}$

1. School of Environmental Science and Engineering, Shanghai Jiao Tong University, Shanghai 200240, China

2. CSSC Nanjing Luzhou Environmental Protection Co., Ltd, Nanjing 210039, China

\section{Figure S1 The full-scale experimental apparatus}

A series of full scale tests were carried out in real coal-fired flue gas. The flue gas flow was about $5.0( \pm 0.5) \times 10^{4} \mathrm{Nm}^{3} \cdot \mathrm{h}^{-1}$. The ozone was injected into the flue gas after the electrostatic precipitator (ESP), and its concentration could be adjusted from 0 to $105 \mathrm{ppm}$. The temperature of flue gas after ESP was about 398-413 K. The concentrations of $\mathrm{NO}, \mathrm{SO}_{2}, \mathrm{O}_{2}$ and $\mathrm{H}_{2} \mathrm{O}$ were about $100 \pm 10 \mathrm{ppm}, 400 \pm 50 \mathrm{ppm}, 5 \%$ and $3 \%$, respectively. The effect of fly ash on $\mathrm{Hg}^{0}$ oxidation could be ignored because the fly ash concentration after ESP was less than $10 \mathrm{mg} \cdot \mathrm{m}^{3}$. The residence time of flue gas in the oxidation reactor was about $2.0 \mathrm{~s}$. Figure S1 was the schematic diagram of the full scale experimental apparatus.

\footnotetext{
* Corresponding author: Telephone/Fax: +86-21-54745591.

E-mail: quzan@sjtu.edu.cn (Zan Qu)
} 


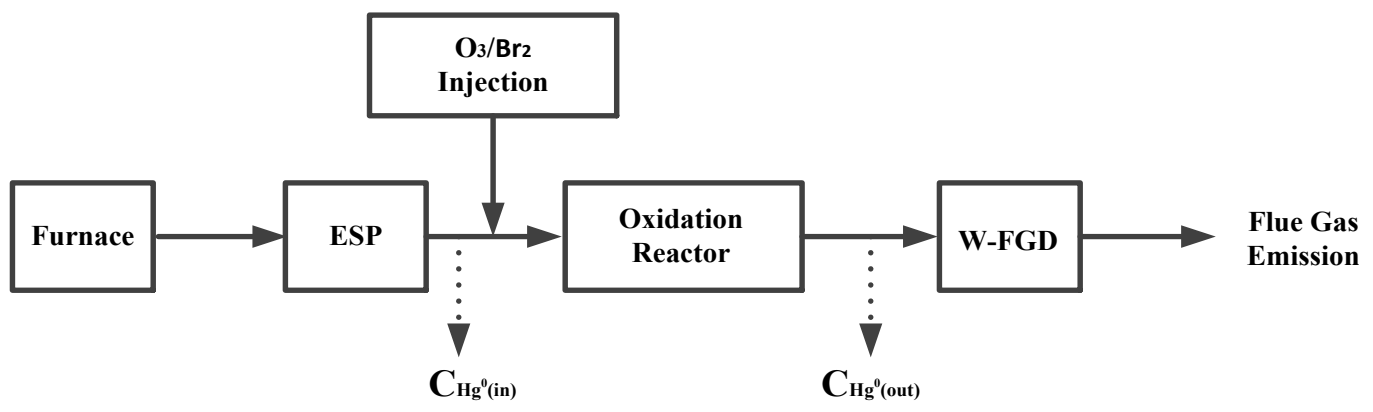

Figure 1. The schematic diagram of the full scale experimental apparatus 


\section{Figure S2. The sensitive analysis on the kinetic model}

The sensitivity of kinetics model was analyzed. As the rate constants at high temperatures (e.g., 400K) are not known for some reactions, we have used the rate constant values reported at lower temperatures (e.g., 298K) for those reactions in the kinetic model. We have conducted sensitivity analysis on these reaction rate constants to evaluate their influences on the model results. The box model was run by using 10 times smaller or larger rate constants for the key reactions, such as $\mathrm{k}_{7}, \mathrm{k}_{9}$ and $\mathrm{k}_{10}$, respectively. As seen in Figure $\mathrm{S} 2$, the $\mathrm{Hg}^{0}$ concentration decrease curves were different when the rate constants were bigger or smaller. However, the change tendency of $\mathrm{Hg}^{0}$ concentration is consistent. Therefore, the results of box model are credible.

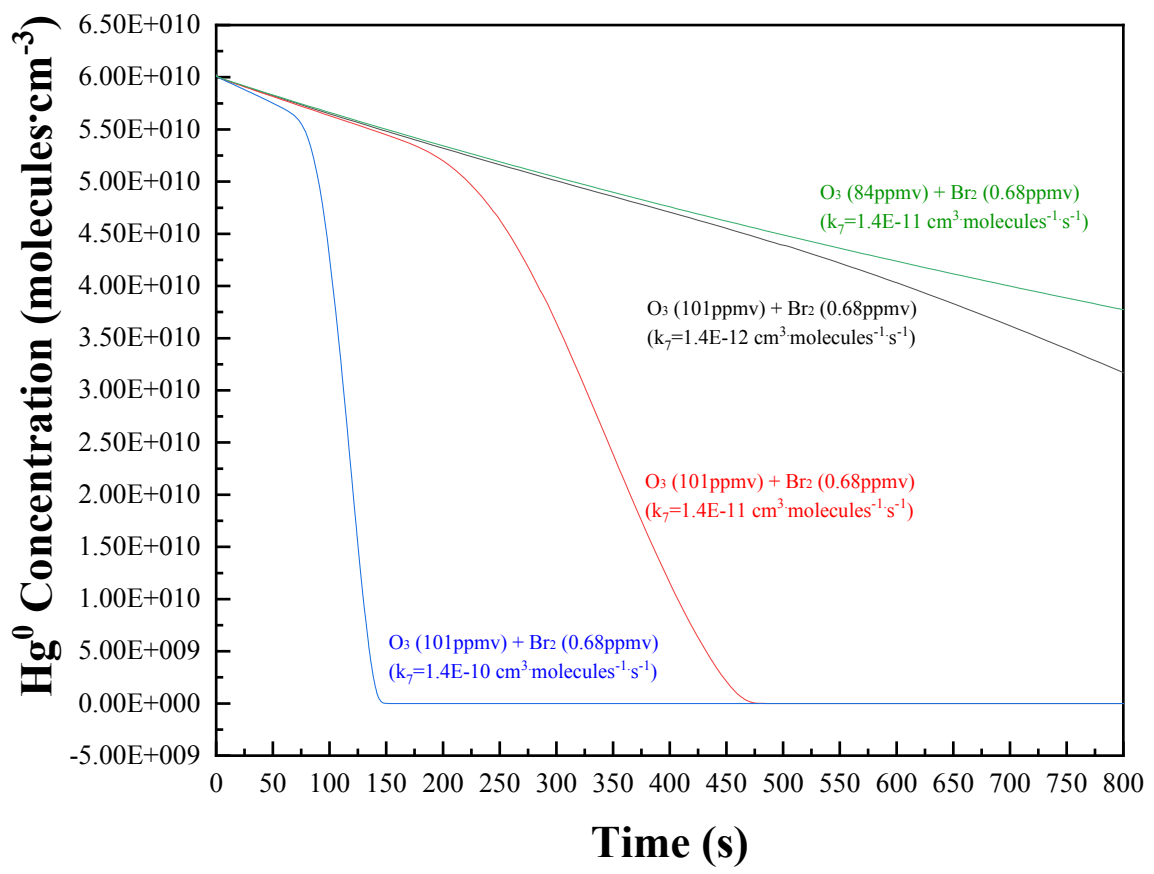

(a) The resutls of box model when $\mathrm{k}_{7}$ was adjusted. 


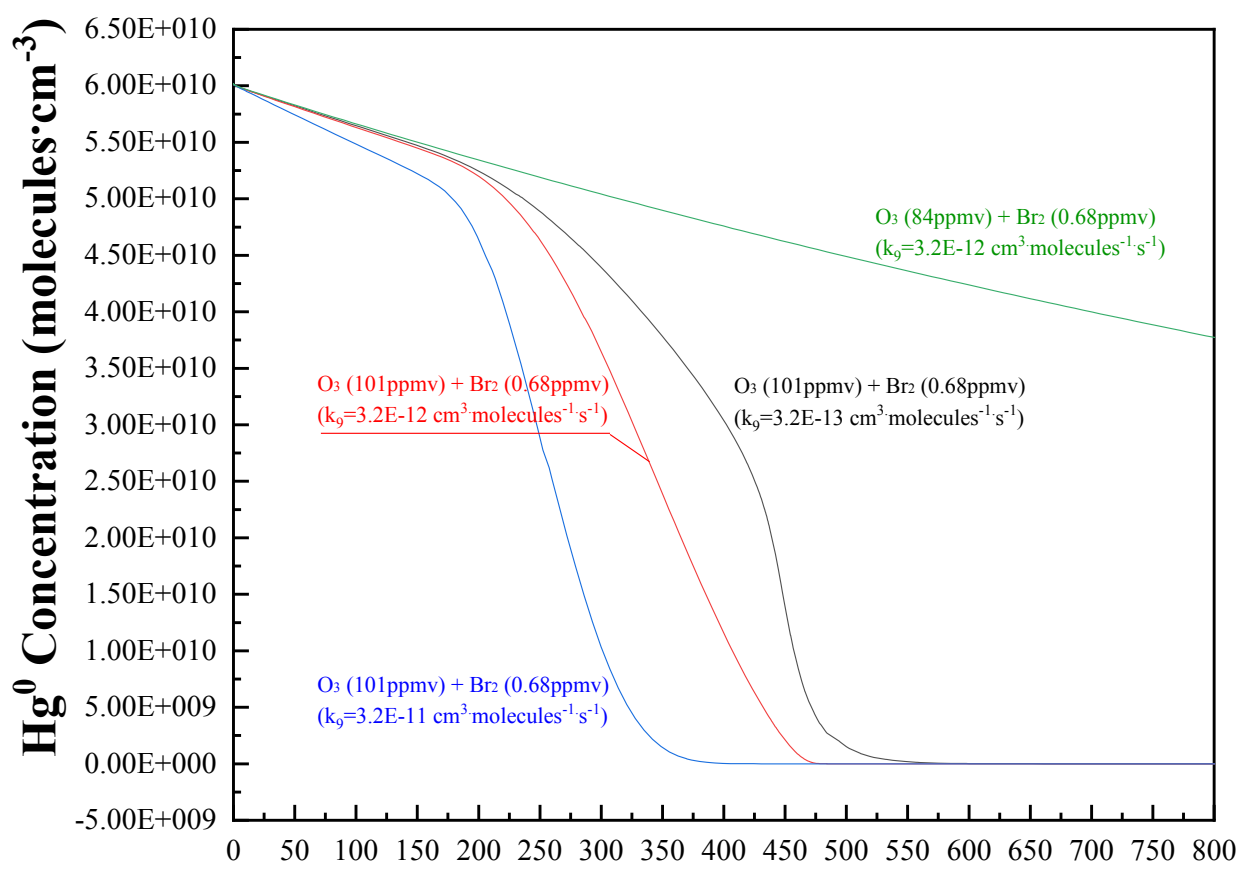

Time (s)

(b) The resutls of box model when $\mathrm{k}_{9}$ was adjusted.

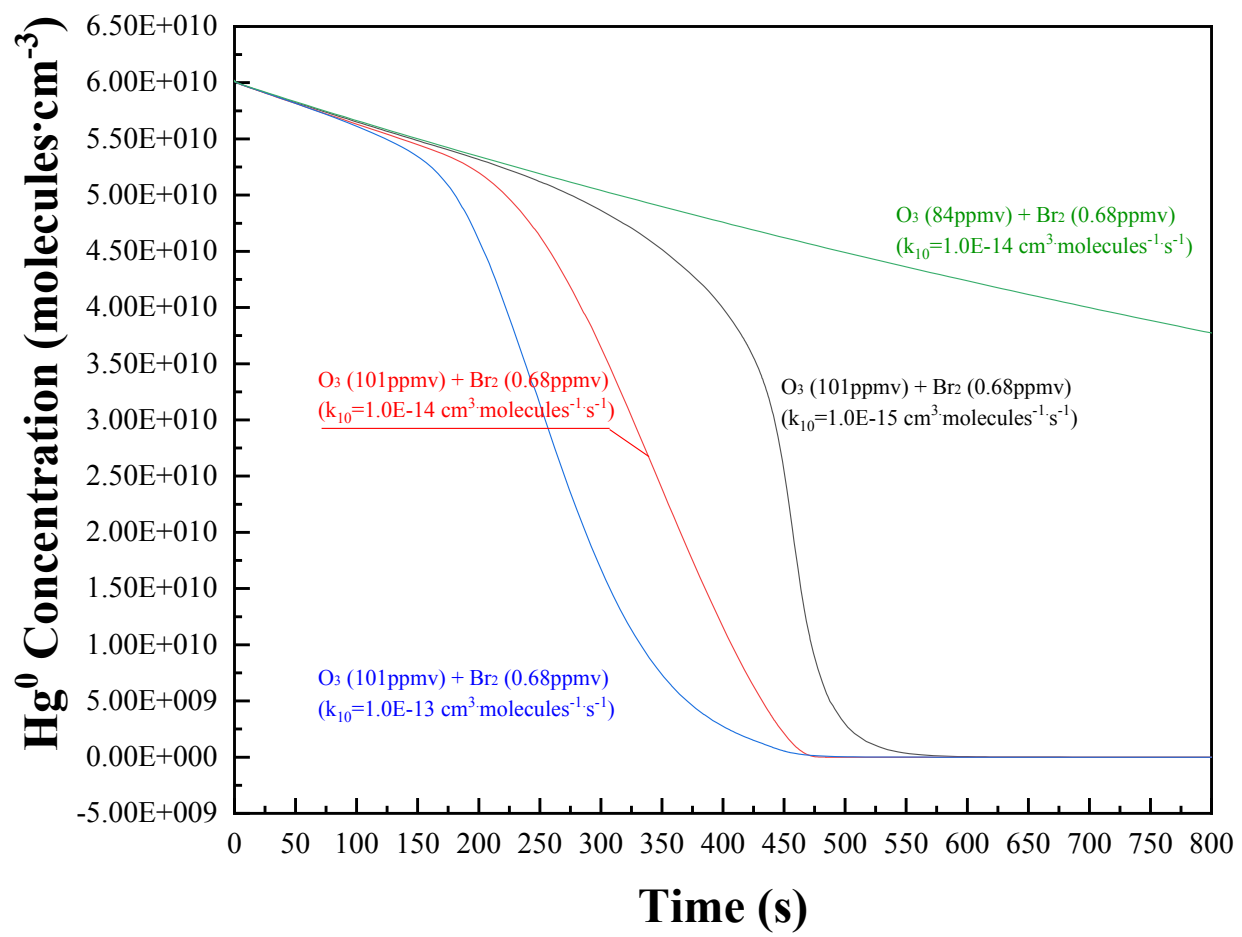

(c) The resutls of box model when $\mathrm{k}_{10}$ was adjusted. 
Figure $\mathrm{S3}$. The $\mathrm{O}, \mathrm{Br}$ and $\mathrm{BrO}$ radicals generate process during the reaction.
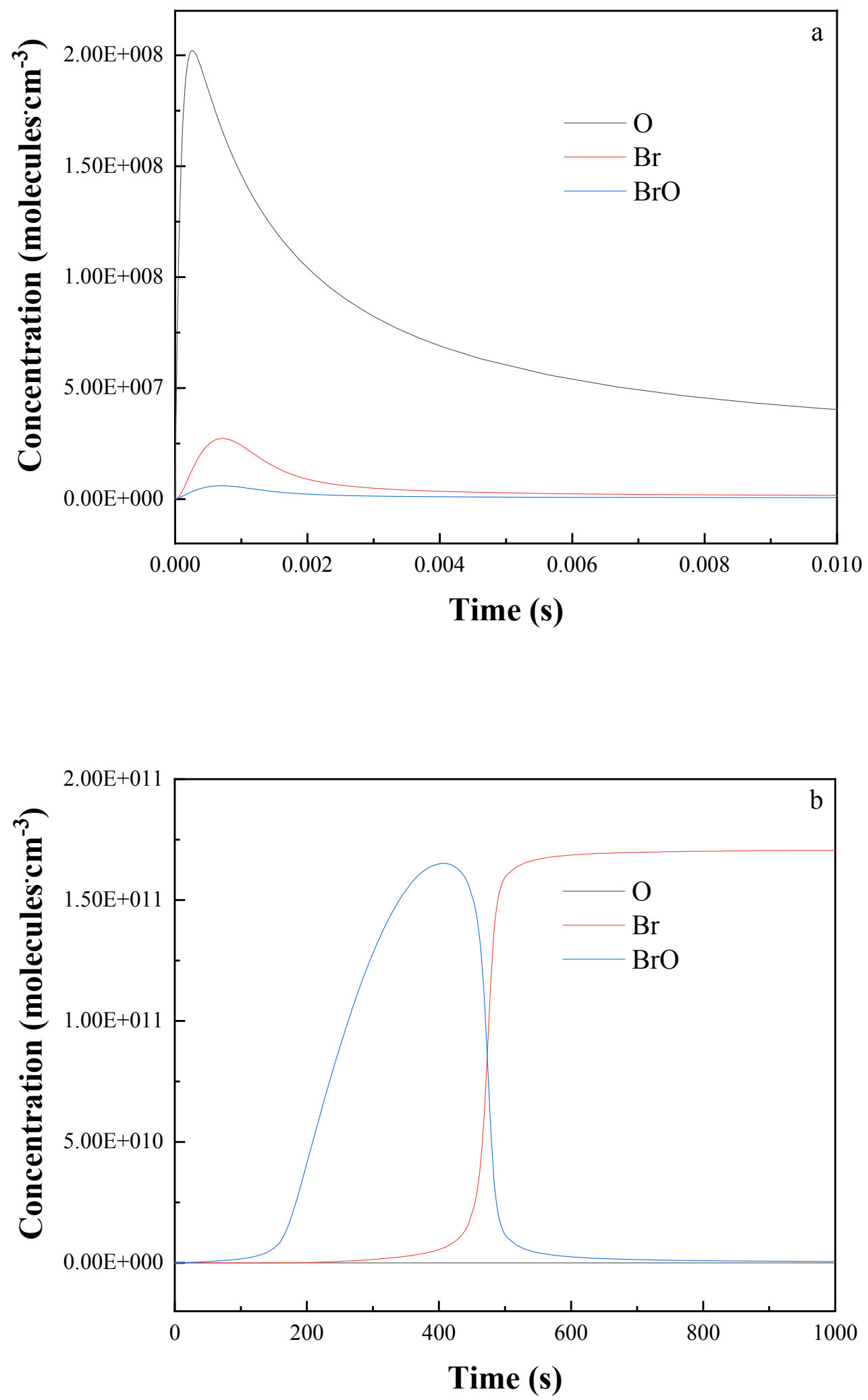
Figure S4. The major products of $\mathrm{Hg}^{0}$ oxidation according to the box calculation.
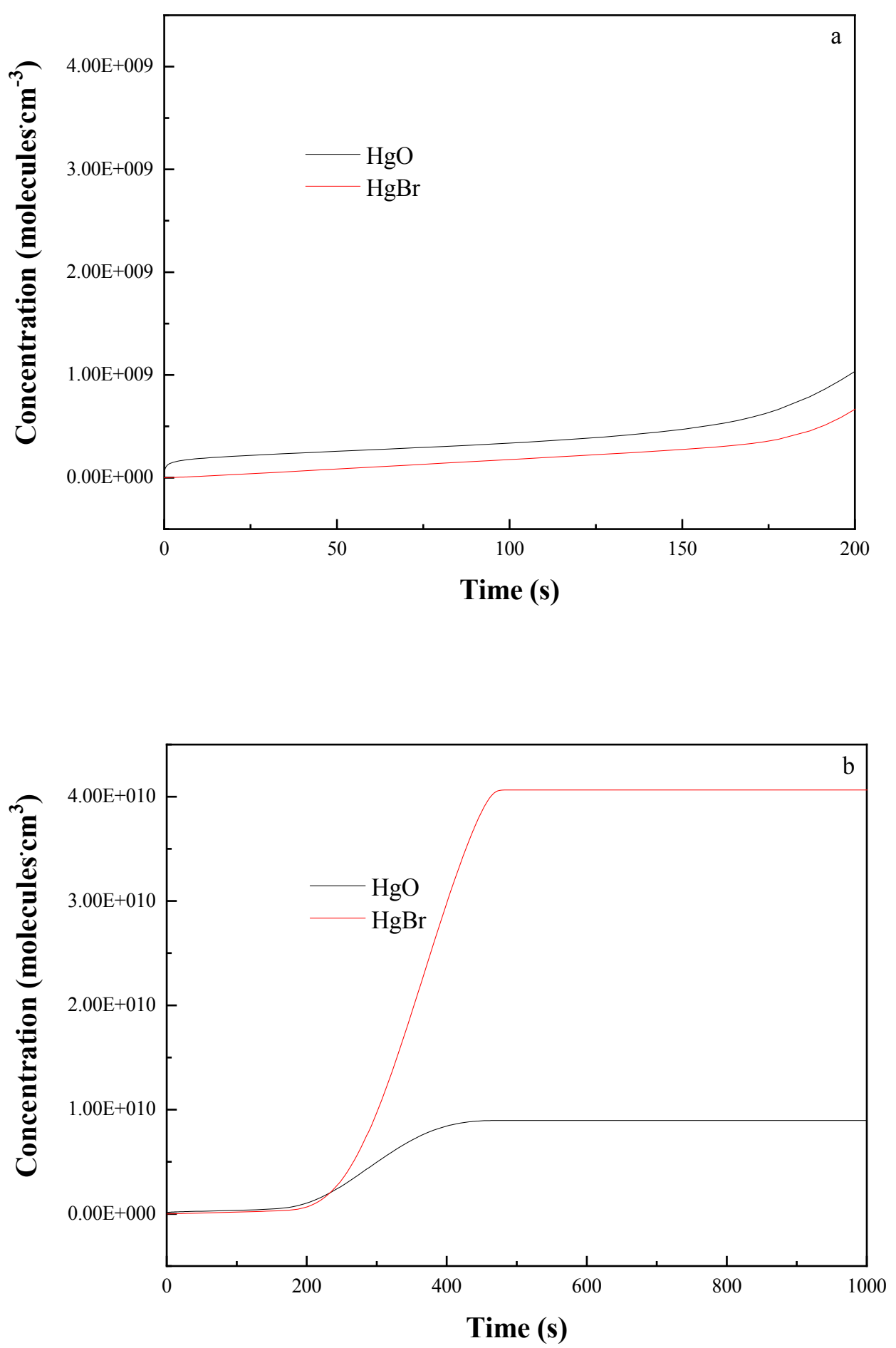